\title{
Strong representationalism and bodily sensations: Reliable causal covariance and biological function
}

Final Draft

\author{
Dr. Sabrina Coninx \\ Philosophical Psychology (2021), 34(2), 210-232
}

Publication:

https://www.tandfonline.com/eprint/QRJHQKEY8D7MYZZAFT5U/full?target=10.1080/095

15089.2020.1858476

Bodily sensations, such as pain, hunger, itches, or sexual feelings, are commonly characterized in terms of their phenomenal character. In order to account for this phenomenal character, many philosophers adopt strong representationalism. According to this view, bodily sensations are essentially and entirely determined by an intentional content related to particular conditions of the body. For example, pain would be nothing more than the representation of actual or potential tissue damage. In order to motivate and justify their view, strong representationalists often appeal to the reliable causal covariance between bodily sensations and certain kinds of bodily conditions or to the corresponding biological function that these bodily sensations are supposed to fulfill. In this paper, I argue on the basis of recent empirical research that arguments from reliable causal covariance and biological function cannot motivate the introduction of corresponding intentional content. In particular, I argue that bodily sensations are caused by a heterogeneous class of physiological and psychological factors and their biological functions are too diverse to be reduced to the representation of a particular bodily condition. Responses are available to strong representationalists, but they either require substantial alterations to their core assumptions or incur a significant empirical burden.

Keywords: Pain; itch; hunger; sexual feelings; better-safe-than-sorry; strong intentionalism; imperativism; representationalism; muscle pain; visceral pain 


\section{Introduction}

Humans undergo a variety of mental phenomena that are characterized by phenomenal character, that is, by "what it is like" to undergo the respective experiences from a first-person perspective. There is something it is like to see a black cat, to smell rotten meat, or to feel a headache. Strong representationalist theories assume that this phenomenal character is essentially and entirely determined by intentional content (e.g., Byrne, 2001; Dretske, 1995; Tye, 1995). Intentionality is the property of mental phenomena which represent existent or non-existent objects, events, or states of affairs. According to strong representationalism, similarities and differences in phenomenology neatly correspond to similarities and differences in intentionality. Strong representationalism is attractive because it enables the reduction of phenomenal character to intentional content which is a naturalistically speaking unproblematic entity. ${ }^{1}$

Strong representationalist theories often focus on exteroceptive sensations, but the general framework is supposed to account for various kinds of phenomenal experiences, including bodily sensations such as pain, hunger, itches, or sexual feelings (Bain, 2003; Byrne, 2001; Cutter, 2017; Dretske, 1995; Tye, 1995, 2007). Accordingly, bodily sensations are supposed to represent objective conditions of the body. For example, pains and their introspectable features are taken to be nothing over and above the representation of a particular bodily condition, usually tissue damage or physiological disturbance (Bain, 2007; Cutter, 2017; Tye, 2005). Due to their intentional content, bodily sensations supposedly possess correctness conditions in terms of whether or not the represented bodily condition corresponds to physical reality (e.g., Bain, 2007). For example, a pain is veridical if the subject's body is damaged or disturbed and it is non-veridical if not.

Opponents of strong representationalism primarily ground their objections in introspectable features. In particular, they emphasize that bodily sensations present themselves subjectively as sensations that do not point to anything beyond themselves (Aydede, 2017, 2019; McGinn, 1996). Irrespective of whether such objections are conclusive (Cutter, 2017; Gozzano, 2019; Tye, 2017), they underestimate the argumentative power of the strong representationalist view. Many strong representationalist arguments do not rely on the introspectable features of bodily sensations, but on their external relations to preceding bodily conditions (e.g., Bain, 2007; Cutter, 2017; Cutter \& Tye, 2011; Tye, 2005, 2007). Bodily sensations represent bodily

\footnotetext{
${ }^{1}$ The assumptions outlined in the previous paragraph are common to strong representationalism and strong imperativism. Both are grouped together as versions of strong intentionalism. The paper focuses primarily on the strong representationalist view. Strong imperativism will be briefly discussed in Section 5.
} 
conditions because they are supposed to occur in the presence of these bodily conditions (see also Coninx, 2020a). Two closely related though not identical lines of argument support this assumption:

Reliable Causal Covariance: bodily sensations represent particular bodily conditions because they causally co-vary in a reliable manner. For example, the causal covariance between pain and tissue damage is commonly taken to be very high. Misrepresentations, that is, non-veridical representations, are possible, but they are supposed to be rare exceptions. $^{2}$

Biological Function: bodily sensations represent particular bodily conditions since their naturally acquired biological function consists in the representation of exactly these bodily conditions. For example, pain represents tissue damage because the pain system was designed (by natural selection) to causally co-vary with tissue damage (e.g., Cutter, 2017; Cutter \& Tye, 2011). Misrepresentations, i.e., non-veridical representations, are possible, but they fail to provide the innate biological benefit that the relevant bodily sensation is supposed to provide.

The aim of this paper is to challenge both arguments. Building on empirical research, I show that neither strong representationalist argument can motivate the introduction of an intentional content accounting for the phenomenal character of bodily sensations. My reasoning turns on the heterogeneity of the causes and biological functions of pain, hunger, itches, and sexual feelings. Bodily sensations are the result of diverse physiological and psychological conditions and their biological function is, in various cases, detached from the veridical representation of a particular bodily condition. ${ }^{3}$

\footnotetext{
${ }^{2}$ Strong representationalists do not provide an unequivocal condition indicating how strong the causal covariance must be between a certain bodily sensation and a certain bodily condition in order to motivate the introduction of a corresponding intentional content. In this paper, I assume that the required reliability must be relatively strong in order to provide a convincing argument in favor of strong representationalism. Accordingly, misrepresentations are supposed to be rare exceptions. This strong criterion corresponds to some of those works that have had a lasting effect on the intuitions underlying representationalist theories (e.g., Pitcher, 1970), while it might seem too demanding to other authors relying on arguments of causal covariance (e.g., Hill, 2017). As already mentioned, the problem is that it is not clearly determined what it means that, for example, pain under normal circumstances occurs together with tissue damage. Thus, the obligation to argue for an alternative criterion lies with strong representationalists, especially as the assignment of a clear cutoff for reliable causal covariance constitutes a general challenge for the plausibility of their position. Many thanks to the two anonymous reviewers who challenged and defended my paper on this aspect.

${ }^{3}$ I do not aim to show that bodily sensations differ in this regard from exteroceptive sensations of vision, audition, taste, smell, and touch. Further investigation must decide whether strong representationalism can convincingly motivate the introduction of an intentional content for exteroceptive sensations on the basis of reliable causal covariance and biological function. It is not uncontroversial that corresponding arguments are successful with
} 
In what follows, I primarily focus on pain. Most strong representationalists outline their theories in reference to this paradigmatic example case. Four points of clarification concerning pain and its intentional content are to be made in advance.

First, in accordance with defenders (Bain \& Brady, 2014; Cutter, 2017) as well as opponents (Aydede, 2000) of strong representationalism, I understand pain as a particular bodily sensation and not as the opposite of pleasure. Pains are not identical to mental phenomena of negative affective valence. Pain is a bodily sensation that is typically experienced as unpleasant, but there are unpleasant experiences that do not count as pains, including other bodily sensations (e.g., itches or hunger), exteroceptive sensations (e.g., the smell or taste of rotten meat), and emotions (e.g., grief or depression). Even if we assume that pains are necessarily unpleasant (Bain, 2014), unpleasantness is not the distinctive mark of their phenomenal character (Bain \& Brady, 2014). I therefore accept that the intentional content of pain itself does not have to account for any affective features. In what follows, I will focus solely on pain and its sensory features. ${ }^{4}$

Second, I take strong representationalism to hold that pain represents tissue damage, though most authors offer alternative bodily conditions (Bain, 2007; Cutter, 2017; Tye, 1997). The notion of tissue damage ideally captures the intuition that there is something specific about the bodily condition that is causally or biologically related to pain. This is of utmost importance. Hunger, itches, and sexual feelings possess phenomenal characters that deviate from the phenomenal character of pain. Bodily sensations possess a unique phenomenal character and, as such, they must represent different bodily conditions. I assume that this is common ground with strong representationalists who aim to account for pain, hunger, itches, and sexual feelings as distinct phenomena related to distinct bodily conditions (e.g., Tye, 1995, 2007).

Third, I acknowledge that pain represents actual as well as potential tissue damage (Raja et al., 2020). I include cases in which the body is already damaged as well as cases in which the

respect to all exteroceptive sensations. For example, there is an active debate about what olfactory sensations represent and whether they represent any particular objective condition at all (Carvalho, 2014; Castro \& Seeley, 2014; Cavedon-Taylor, 2018).

${ }^{4}$ In everyday life, it may seem difficult, if not impossible, to separate sensory and affective aspects, as we typically experience them as an integrated unit. Especially cases of pain asymbolia have contributed to the now widespread assumption that sensory and affective features of pain can, in principle, occur independently (Bain, 2014; Corns, 2014; Grahek, 2007; Klein, 2015). For the sake of the envisaged argument, I will presuppose that this assumption is uncritical. Furthermore, it should be noted that in order to account for the affective features of pain, some strong representationalists introduce a second evaluative content (Bain, 2013, 2017). According to this view, the intentional content of unpleasant pains is composed of the representation of a certain bodily condition plus the representation of this bodily condition as bad for the subject. Whether strong representationalism can conclusively account for the affective features of pain and other mental phenomena must be the subject of independent debate (e.g., Corns, 2018; Jacobson, 2013). 
body is dangerously close to being damaged in the near future (Hall, 2008; Pitcher, 1970). For example, I take it that a pain that is caused by a source of increasing pressure veridically represents damage even if this damage is not yet present but likely to occur at any moment. Moreover, I assume that it is only when subjects experience pain that this pain is supposed to be reliably caused by actual or potential damage or to reveal the biological function of representing damage (Hill, 2012; Pitcher, 1970). Considerations concerning the absence of pain in the presence of tissue damage, or concerning the biological connection between other mental phenomena and tissue damage can thus be put aside.

Fourth, although the presupposed intentional content need not determine the affective features of pain, it must account for its sensory features. Strong representationalists commonly assert that pains possess felt location and intensity (Cutter, 2017). Some pains are felt as being located in the joints, others in muscles or inner organs. Some pains are felt as moderate in intensity, others as mild, and yet others as severe. The intentional content of pain must account for these differences in phenomenology. Most strong representationalists consider the felt location of pain to represent the body area in which tissue damage is located (Bain, 2007; Tye, 2005), while the felt intensity of pain seems to represent the severity of damage (Cutter, 2017; Hill, 2012). ${ }^{5}$

The paper proceeds as follows. In Section 2, I focus on the argument from reliable causal covariance. I show that non-veridical representations are not rare exceptions from the norm. This is due to the heterogeneity of causal factors that affect pain and its sensory features. In Section 3 , I show that this applies in a similar manner to the biological function of pain. The biological benefits that pain provides are too diverse to be plausibly characterized by the representation of actual or potential tissue damage. In Section 4, I extend my conclusions concerning pain to other bodily sensations of hunger, itches, and sexual feelings. Although each bodily sensation has idiosyncratic characteristics, all prove resistant to strong representationalist arguments from reliable causal covariance or biological function. In Section 5, I discuss possible strategies for strong representationalist responses. I argue that each strategy comes at a high price while none proves to be particularly attractive for defenders of strong representationalism. Section 6 summarizes the results of my investigation.

\footnotetext{
${ }^{5}$ For the sake of simplicity, I will neglect so-called sensory qualities (e.g., pulsing, burning, aching, stinging, or cramping) which have rarely been considered by strong representationalists (Cutter \& Tye, 2011).
} 


\section{Reliable Misrepresentations}

If pain reliably co-varies with actual or potential tissue damage, then misrepresentations should be rare exceptions to the norm. Strong representationalists assume that pain does reliably covary with a distinct bodily condition, so they have the burden of empirical proof. Unfortunately, such proofs are not be found in the literature, where intuitions play a driving role. This might be due to the lack of comprehensive statistical analyses of pains and their occurrence in the absence or presence of tissue damage. ${ }^{6}$ Notwithstanding, I aim to show that empirical studies reinforce significant doubts about a reliable causal covariance between pain and tissue damage. Recent research indicates that cases in which pains occur in the absence of tissue damage cannot be considered rare exceptions in any plausible sense. I argue for this claim on the basis of three facts. ${ }^{7}$

First, misrepresentations prototypically occur in chronic pains (Corns, 2014). Many chronic pains are characterized by the occurrence of pain in the absence of a corresponding actual or potential damage because they rely on alterations to the peripheral or central nervous system (Apkarian, Baliki, \& Geha, 2009; Treede et al., 2019). Although most types of chronic pain, such as phantom pain or fibromyalgia, occur as separated phenomena in a small group of the population, the total number of people with such conditions should not be underestimated: persisting pains affect, on average, about $20 \%$ of the population (Breivik et al., 2006; Dahlhamer et al., 2018). As such, the number of such cases exceeds the number of analogous chronic conditions considered to be non-veridical representations of exteroceptive sensations. For example, chronic tinnitus affects, on average, "only" $10 \%$ of the population (Bhatt, Lin, \& Bhattacharyya, 2016).

Second, episodic pains can occur in the absence of actual or potential tissue damage. Relatively common in everyday life is, for example, the acute fast-fading occurrence of muscle pain during or immediately after performing physical activities. Although different factors, such as metabolic processes, are involved in the generation of this pain, no actual bodily damage is known that could be assigned as its cause (Miles \& Clarkson, 1994). Subjects also

\footnotetext{
${ }^{6}$ Data available from hospitals or physicians cannot provide the required basis for such analyses because various pains experienced in everyday life, such as the pain of cutting a finger on paper, are not systematically collected. Subjective reports alone do no better because laypeople often cannot adequately evaluate whether an experience of pain is caused by tissue damage or not.

${ }^{7}$ In the past, similar objections concerning dissociations between pain and tissue damage have been brought forward (Coninx, 2020a; Corns, 2014; Klein, 2015, 2017). In this section, I aim to connect these objections on the basis of recent empirical data and extend them in light of examples that have thus far received too little attention (e.g., visceral pains). In the upcoming section, I also close possible loopholes for strong representationalists in reference to the biological function of pain.
} 
start to experience the pain of physical exertion long before any potential damage could occur in the muscles or before the body collapses from exhaustion (Klein, 2017). During the performance of physical activities, subjects cannot be constantly close to suffering from some sort of tissue damage, given that most physical activities do not lead to such a result. Even the sore muscle pain which comes after a delay of hours or days after physical activity is not necessarily associated with muscle damage or inflammation, as scientists had believed it was for a long time (Mizumura \& Taguchi, 2016; Murase et al., 2010).

Third, the sensory features of location and intensity do not fit well with the relevant physiological features of tissue damage. This makes a reliable causal covariance between the intentional content of pain and the objective condition of the subject's body even less plausible. Multiple cases expose the systematic mismatch between the physiological features of tissue damage and the sensory features of pain. Problems of location and intensity will be discussed in turn.

The location of tissue damage does not always neatly correspond to the location in which pain is experienced. Visceral pains are particularly interesting and pressing cases because they constitute one of the largest subclasses of pain (Halder \& Locke III, 2009). Visceral pains are often experienced as vaguely located, although they often have a precise point of origin (Strigo et al., 2002). Pain in the intestine might be caused by a spasm of a certain muscle or by the inflammation of a particular segment, such as the appendix. Meanwhile, the subject experiences pain across a larger area of the lower abdominal region. The represented location might include the actual location, but it fails to represent the exact spatial features of tissue damage. One might reply that it is sufficient that the represented location includes the actual location of tissue damage. This reply entails implausible consequences. For instance, people who experienced pain in their entire body would veridically represent a tissue damage located in the fingertip. One might further debate the degree of vagueness that should be admitted when the felt location of pain differs from the objective location of damage; however, in the absence of a clear criterion that distinguishes veridical from non-veridical representations, strong representationalism loses its argumentative strength.

The list of cases in which the felt intensity of pain fails to correspond to the severity of the corresponding tissue damage is almost endless because many different factors have an impact on subjective intensity (e.g., Apkarian, 2017; Brooks \& Tracey, 2005; Bingel \& Tracey, 2008; Ploner, Bingel, \& Wiech, 2015). Sensory intensity is affected by various interoceptive and exteroceptive signals. For example, simultaneous vibration can decrease and increase the felt intensity of pain depending on experimental conditions (Melzack, Wall, \& Weisz, 1963). 
Similarly, seeing one's own body in contrast to a neutral object reduces pain intensity (Longo et al., 2009). Psychological factors also have an impact on the intensity of pain. For example, the expectation of pain relief (Howick et al., 2013) and social support from significant others (Brown, 2003) leads to a decrease in the intensity of pain. On the other hand, anxiety (Rhudy, 2016) and the subjective anticipation of future pain (Keltner, 2006) lead to an increase in pain intensity. Given the systematic influence of such common factors on the felt intensity of pain, the chance that it neatly corresponds to the severity of tissue damage becomes very small (Coninx, 2020a). ${ }^{8}$

In sum, these insights indicate that pain is related to a heterogeneous class of causes. There is no unilinear relation between pain and tissue damage, as many philosophers assume. Consequently, the focus on tissue damage constitutes a significant oversimplification of the causal relations involved in pain. Interestingly, this has been uncontroversially accepted by scientists across academic disciplines, such as psychology, neuroscience, and clinical medicine (e.g., Gatchel et al., 2007; Hadjistavropoulos, 2017; Melzack \& Wall, 1982). If we take these empirical results seriously, so-called non-veridical representations can hardly be considered to be rare exceptions. Taking into account all the facts presented, the opposite seems to be the case.

\section{Better-Safe-Than-Sorry}

In the previous section, I provided evidence that pain and tissue damage do not causally covary in a reliable manner. This objection does not necessarily affect the second line of argument brought forward by strong representationalists: namely, pain represents tissue damage because it is its biological function to do so. Accordingly, pain is supposed to reliably co-vary with tissue damage, at least under those conditions for which pain was naturally designed. In order to make this argument work, strong representationalists must assume that the naturally acquired function of pain relies on a "better-safe-than-sorry" principle (Millikan, 2004). That is, to account for frequently occurring misrepresentations, strong representationalists must assume that residual veridical representations increase the probability of survival overcoming the biological costs brought about by non-veridical representations.

This assumption has two important implications. First, those cases in which pain and its sensory features dissociate from tissue damage and its physiological features must be false alarms that do not contribute, by themselves, to the biological benefit that pain generally

\footnotetext{
${ }^{8}$ Lately, this issue has been recognized by at least some strong representationalists (Cutter, 2017).
} 
provides. Only veridical representations fulfill the biological function that pain was naturally designed for. Second, the ecological costs of pains must be relatively low. Otherwise, it is unlikely that the biological benefits of veridical representations overcome the biological costs of non-veridical representations, especially as misrepresentations are not rare exceptions. In this section, I argue that both implications are implausible.

First, those pains that do not veridically represent tissue damage are supposed to constitute false alarms that fail to provide the innate biological benefit for which pain was naturally acquired. Most plausibly, this biological benefit is somehow grounded in the promotion or protection of the subject's bodily integrity (Williams, 2017). Accordingly, non-veridical representations do not contribute by themselves to the physiological well-being of the subject. The classification of manifestations of chronic pain, such as phantom pain or fibromyalgia, as "pathological" appears plausible because they fail to provide any biological benefit. ${ }^{9}$ This does not necessarily apply to all pains labeled as non-veridical (Coninx, 2020a; Klein, 2015). Many promote the physiological well-being of the subject even though they are not veridical representations of actual or potential tissue damage.

Pains felt during or immediately after physical performance are not associated with actual or potential tissue damage. Instead, they seem to function as indicators for the subject's level of exertion. Identifying the level of exertion is relevant for the subject's ability to function at the edge of their bodily limits without collapsing or underloading. For instance, the introspective rating of physical exertion proves to be highly useful in promoting muscle growth and gaining physical strength (e.g., Borg, 1998; Helms et al., 2018; Zourdos et al., 2016). Moreover, muscle pain might prevent the subject from depleting the physical resources required for the performance of other survival-relevant activities, such as fighting and fleeing. ${ }^{10}$

Visceral pains are not made less adaptive by their failure to represent the precise location of tissue damage. In many cases, subjects cannot act on the relevant body part in a precise manner, as the muscles of inner organs are not under voluntary control. Notwithstanding, visceral pains still contribute to the promotion and protection of a subject's bodily integrity. For example, in the case of intestinal pain, subjects often massage or warm their entire lower abdominal wall.

\footnotetext{
${ }^{9}$ It is uncontroversial that these pains constitute pathological disorders. This does not mean that they are pathological because they are non-veridical representations.

${ }^{10}$ The case of delayed muscle soreness is more difficult because it is still up for debate what biological function it might serve. Some authors ascribe a warning function which demands the limitation of movement; others argue, in reply, that further performances do not affect the recovery process of the muscles (Nosaka, 2008).
} 
This behavior can be adaptive by increasing the blood flow and relaxing spastic muscles, irrespective of their exact location.

Strong representationalists must account for all the factors that affect the felt intensity of pain besides tissue damage. According to their position, these factors must be considered as debilitating or distorting because they prevent the subject from veridically representing the severity of the damage (Hill, 2012). In contrast, it appears to be beneficial that the experience of pain is shaped by stimuli from multimodal sources. In particular, both interoceptive and exteroceptive signals provide information about the body's condition and one's possibilities for acting upon it. For instance, the influence of visual signals might be functionally grounded in the fact that they allow the subject to identify and control the pain-causing stimuli, at least in the case of superficial pains. In the presence of the same tissue damage, differences in felt intensity can also be beneficial in light of varying emotional contexts. For instance, it appears adaptive that subjects react in different manners when they experience themselves as being in a safe environment versus a dangerous one, as these environments demand different reactions.

Second, I note that the "better-safe-than-sorry" principle is prototypically associated with reflexes, such as the eye-blink reflex (Millikan, 2004). The biological function of the eye-blink reflex seems to be adequately described as promoting the protection of the eye, given that, for this kind of automatic reaction, the positive outcome of a few correct reactions outweighs the quite low energy and resource costs of many false alarms. The "better-safe-than-sorry" principle might work for various phenomena. However, we have reason to doubt that this applies to pain because its biological costs are exceptionally high.

Pain demands attention, interrupts cognitive processes, limits movements, influences motivational focus, and brings about an emotional burden (e.g., Apkarian, Bushnell, \& Schweinhardt, 2013; Eccleston \& Crombez, 1999; Hadjistavropoulos, 2017; Melzack \& Wall, 1982). This is the reason why pain has such an immense impact on the quality of life of concerned subjects (e.g., Ilgen et al., 2010). The biological benefit of pain must not only be compared to the negative effects of those cases in which people fail to experience pain in the presence of tissue damage, but one must also take into account the ecological effects of every case that the representational view labels as a non-veridical representation. A process with such high production costs as pain should, in general, be successful rather than unsuccessful in order to reduce the waste of energy and resources relevant for survival (Klein, 2015). The rare exceptions should turn out to be pathological cases, such as phantom pains. 
It should be noted that ecological costs are not identical to disadvantages. A system with high ecological costs can be adaptive, given that its general outcome brings about a corresponding biological benefit, and I certainly agree that pain provides such benefit. Nonetheless, given that pain has high ecological costs, it appears implausible that it would work on a "better-safe-than-sorry" principle. ${ }^{11}$

In reply to these objections, strong representationalists might argue that pain originally evolved as a system for damage indication while the adaptive function of false alarms emerged later as a beneficial side-effect. This form of functional re-use is frequently labeled exaptation. Applying this concept to pain offers the opportunity to define the biological function of pain as the representation of tissue damage. It allows misrepresentation to be considered beneficial, though with respect to an additional benefit that non-veridical representations developed later on. This solution has several problematic implications, however.

For the solution to work, multiple processes of exaptation must have taken place. We do not merely need to assume that, for instance, the pains of physical exertion have found an additional adaptive function. The influence of all those physiological and psychological factors responsible for misrepresentations of the severity of tissue damage must also have developed through separate processes of exaptation. This multiplicity makes the proposed solution seem $a d-h o c$, and its defenders must provide more sequentially differentiated evidence. In addition, this solution is necessarily based on the assumption that pain evolved in organisms at an early evolutionary stage, and that the pain system of these organisms is exclusively related to tissue damage. This attempt to save the argument from biological function to strong representationalism thus comes with huge empirical burdens that are, at least to this date, not supported by the research.

It is still up for debate whether animals which developed at an early evolutionary stage, such as fish, are able to experience pain (e.g., Key, 2015; Sneddon, 2015; Sneddon et al., 2014). Even if we accept this as given, the biological function of pain in fish cannot plausibly be the representation of tissue damage and its physiological properties. The system that is most likely associated with the generation of pain in such animals is also affected by factors other than tissue damage, given that even fish possess an endogenous opioid system (Machin, 2001; Wolkers et al., 2013). This system has been shown to be responsible for the lack of perfect

\footnotetext{
${ }^{11}$ In reply, one might argue that it is better to have a system that produces many misfires with significant biological costs than to have no system for the representation of damage at all. For example, the chance of survival of patients suffering from pathological pains is still higher than that of people suffering from congenital analgesia (e.g., Nagasako, Oaklander, \& Dworkin, 2003). However, it remains questionable that this is in fact the default strategy that has prevailed in evolution with regard to one of the most vital systems for most organisms.
} 
correspondence between the sensory properties of pain and the physiological properties of tissue damage in mammals. Consequently, strong representationalists must appeal to insects or invertebrates. However, it currently appears empirically impossible to decide whether such animals experience pain or not.

In sum, pains prove to be adaptive in multiple ways, many of which are independent of the veridical representation of tissue damage. By defining the biological function of pain as the veridical representation of tissue damage, too many pains must be considered pathological or at least as failing to contribute to the biological benefit that pain was naturally designed to provide. Considerations of a "better-safe-than-sorry" principle or evolutionary exaptation are either implausible or carry significant empirical burdens.

\section{Itches, Hunger, and Sexual Feelings}

The considerations set out above are consistent with the view that pain is a unique case and that other bodily sensations do not produce the same problems for strong representationalism. In this section, I consider other bodily sensations in order to show that they are equally challenging.

Strong representationalists rarely offer a clear characterization of the bodily conditions that sensations other than pain, such as itches, hunger, and sexual feelings, are supposed to represent. They are often described merely as some sort of physiological changes taking place in certain parts of the body, such as the skin, stomach, or genitals (Tye, 2007). This is not incidental. For itches, hunger, or sexual feelings, there is a clear lack of immediately plausible candidates for the bodily conditions to be represented by the corresponding bodily sensation. Of course, strong representationalists can respond that it is up to empirical research to reveal the bodily conditions that are causally and biologically connected to the relevant phenomenal experiences. However, again, empirical research indicates a heterogeneity of causes and biological functions which prevent the fixation of an intentional content that determines the corresponding phenomenal character.

First, we might best identify itches with the representation of some sort of skin irritation that is, in contrast to pains, not related to any actual or potential damage. However, itches can have multiple causes, and many of them do not, even on a charitable reading, correspond to this description. Itches can be caused by substances secreted by animals and plants, dermal infections and inflammations, allergens, drugs, neural disorders, or psychopathologies (Lavery et al., 2016; Misery, 2016). The sensory properties of itches are also affected by a variety of 
multimodal signals (Azimi, Xia, \& Lernera, 2016) as well as by psychological factors (Han \& Dong, 2014; Misery et al., 2018). Moreover, the causal and biological properties of itches are primarily characterized in terms of the scratching behavior that itches elicit and not in terms of a preceding bodily condition that might reliably co-vary with itches (Lavery et al., 2016; Mochizuki \& Kakigi, 2015). The scratching behavior elicited by the itch might be decisive for its adaptive benefit, rather than the physiological condition that causes the sensation (Hall, 2008). For example, scratching might be beneficial, as it removes substances from the skin's surface that are poisonous, irritating, or searing.

Second, given its introspectable features, hunger might best represent contractions of the stomach walls which relate to the emptiness of the organ (Tye, 2007). On the contrary, the amount of stomach contents is not a decisive factor for the experience of hunger. The biological function of hunger seems to be grounded in energy balancing, which is related to various relevant factors, such as blood sugar level, hormone levels, olfactory signals, stress, and environmental conditions (Amin \& Mercer, 2016; Burger, Sanders, \& Gilbert, 2016; Huh et al., 2015; Mayer, 1996). Meanwhile, hunger cannot simply represent a low energy level, at least not if the intentional content is supposed to account for the felt location of hunger. References to a low energy level fail to explain why hunger is experienced as being located in the stomach, which is just one organ that is sensitive to, for example, the subject's blood sugar or hormone levels. By contrast, it might be, again, that the behavior elicited by hunger plays the decisive role for its biological function: the search for and ingestion of nutrition (e.g., Klein, 2015).

Third, orgasms, or sexual feelings in general, constitute a particularly interesting case. Orgasms and other sexual feelings can be caused by the mechanical stimulation of sensory areas with a high density of receptors found, for example, in genitals. This corresponds to the fact that they are experienced as being located mainly in these body parts. However, orgasms can be caused by the mechanical stimulation of various other body parts, as well as by dreams, drugs, or the imagination (Komisaruk \& Whipple, 2011). In addition, orgasms and sexual feelings are highly affected by a variety of psychological factors (e.g., Brotto et al., 2016; Nekoolaltak et al., 2017). Most importantly, their biological function is clearly not grounded in the representation of a particular bodily condition, such as the sensory stimulation of a particular body part. Representations of mechanical stimulation fail to account for the actual biological function of orgasms and sexual feelings, which are related to maximizing reproduction, forming pair-bonds, and improving mate choice (Fleischman, 2016; Safron, 2016). 
In sum, bodily sensations, such as pain, hunger, itches, or sexual feelings constitute a challenge for the strong representationalist who aims to justify the introduction of a corresponding intentional content by appealing to external relations of reliable causal covariance or biological function. While every bodily sensation can have its own characteristics, the heterogeneity of their causes and biological functions is the primary factor that prevents the fixation of a corresponding intentional content which determines their phenomenal character. Strong representationalists fail to account for the fact that bodily sensations are the product of a heterogeneous class of physiological and psychological factors. Meanwhile, their biological functions often have no direct connection to the veridical representation of a particular bodily condition. By contrast, the previous considerations indicate that the actions elicited by bodily sensations play a more significant role. Similar issues might occur in the investigation of thirst, dyspnea, or thermal sensations.

\section{Possible Responses}

In reply to my objections, strong representationalists might rely on a few different strategies. In this section, I will discuss the most promising. Each of them allows strong representationalists to avoid some of the previously discussed issues, but at a high price. In particular, each strategy diminishes the intuitive plausibility of the strong representationalist view.

First, strong representationalism might define the intentional content of bodily sensations in terms of a disjunctive list of all those bodily conditions that are causally and biologically related to them, but not to other bodily sensations. For example, one might assume that pain represents actual tissue damage or potential tissue damage or certain disorders of the central nervous system or some metabolic processes or something else along those lines. We might relate itches to the representation of poisonous substances or irritating substances or dermal infections $o r$ particular neural disorders or something along those lines. We might even extend this disjunction to include combinations of these bodily conditions and relevant psychological factors. This solution allows strong representationalists to account for the heterogeneity of the causes and biological functions of bodily sensations. However, it is in tension with the main motivation of strong representationalism. Strong representationalism aims to identify a particular objective condition that pains or itches might represent in order to account for their distinct phenomenal character (Klein, 2015). 
Second, strong representationalists might attempt to alter the intentional content of bodily sensations. As the most prominent example, one might assume that bodily sensations do not represent objective bodily conditions but, rather, the subjective relevance of certain stimuli. This solution seems attractive at first glance, but it leads to a serious demarcation problem. ${ }^{12}$ We will consider this strategy first with respect to pain, then itches and hunger, and then sexual feelings.

One might assume that pain does not represent tissue damage but an actual or potential harm. This alternative interpretation of the intentional content of pain is roughly based on a strategy developed by Christopher Hill (2012). According to this approach, the intensity of pain does not represent the severity of a stimulus, but its degree of harm, that is, the degree to which a stimulus impairs the proper biological functioning of an organism. To which degree a stimulus harms the proper biological functioning of an organism might depend on multiple factors, including sensory and psychological aspects. For example, tissue damage of a certain severity can impair the proper functioning of an organism in different manners depending on whether the organism is located in a safe or a dangerous environment. Thus, the excitatory or inhibitory influence of multisensory signals or psychological factors on pain intensity need not be considered as debilitating or distorting because they contribute to the representation of more or less harm in a veridical and biologically beneficial manner.

In accordance with this interpretation, we might also assume that pain represents different bodily conditions that are in some way or another harmful for the physiological well-being of a subject, even if they are not directly related to actual or potential damage. For example, we might interpret muscle pains as indicating the exertion of relevant resources which could, in the long run, lead to harm by preventing survival-relevant activities, such as fight or flight reactions. Moreover, one might assume that the location of harm could vary to a certain degree from the location of a corresponding bodily cause, such as in the case of visceral pains. Even if only a certain part of the intestinal system is inflamed, this inflammation might harm the proper functioning of the larger area in which the pain is experienced. In this way, the number of non-veridical cases shrinks significantly.

Interestingly, this strategy can also be applied to itches and hunger. Contact with poisonous or otherwise intolerable substances, as well as inflammations and irritations of the skin, are harmful for the subject. Moreover, on this interpretation, we can account for the influence of

\footnotetext{
${ }^{12}$ I am thankful to an anonymous reviewer for emphasizing this point. Interestingly, the problem of demarcation seems to be pressing for both indicative as well as imperative versions of strong intentionalism (Coninx, 2020a, 2020b).
} 
psychological factors on itches. Most prominently, itches are highly contagious: subjects tend to experience itches when they see other people performing scratching behavior (Misery et al., 2018). We might explain this fact by positing that the behaviors of others constitute social cues for a potential harm in the environment, such as the presence of certain plants or insects. Similarly, we might posit that a subject's blood sugar level or environmental conditions constitute indicators for the physiological harms of malnutrition or starving while hunger promotes the subject's protection from exactly this harm.

What might first appear as an advantage constitutes a serious problem. Pain, itches, and hunger all appear to be related to harmful conditions that affect the subject's physiological well-being in a more or less proximate sense. Following the outlined approach, considerations concerning reliable causal covariance and biological function show that the intentional contents of multiple bodily sensations collapse in the representation of actual or potential harm. Phenomenal differences between pain, hunger, and itches thus cannot be explained in terms of their intentional content. This conclusion contradicts the main assumption of strong representationalism that every difference in phenomenology relies on a corresponding difference in intentionality. Thus, the suggested intentional content of bodily sensations fails to account either for the heterogeneity of their respective causes and biological functions, or for the phenomenal differences between pain, hunger, and itches.

A similar problem might occur in the case of orgasms and sexual feelings, as the fixation of a concrete intentional content is a balancing act between the problem of heterogeneity and the problem of demarcation. On the one hand, the intentional content must be flexible enough to do justice to the influence of various physiological and psychological factors. This condition must be fulfilled if the intentional content is to be motivated by arguments of reliable causal covariance and biological function. On the other hand, the intentional content needs to account for sensory features, such as felt bodily location, and distinguish the relevant bodily sensations from closely related, though not identical phenomena, such as romantic affection.

Third, one might object that I have presupposed a misguided version of representationalism and that the objections raised above can be avoided by other versions of representationalism. On the one hand, one might defend a weak version of representationalism (e.g., Block, 1990). According to this view, the intentional content does not exhaust the phenomenal character of an experience. That is, similarities and differences in phenomenology might not be exclusively grounded in similarities and differences in intentionality. Various challenges to strong representationalism could then be avoided because the intentional content of bodily sensations 
need not perfectly match the features of a certain physiological condition. However, this would lose one of the main advantages of strong representationalism: the naturalization of bodily sensations in terms of an intentional content that essentially and exhaustively determines their phenomenal character.

On the other hand, one might hold the position of strong representationalism while including intentional modes. The phenomenal character of bodily sensations would then be exhausted by their intentional content in combination with their intentional mode, that is, the particular manner in which the content is presented to the subject (Crane, 2003). For example, pains and itches might possess the same intentional content presented under different modes. This would solve the demarcation problem. However, we are then left to wonder why we should assume that different bodily sensations are related to different intentional modes. In particular, if arguments of reliable causal covariance and biological function are relevant, then significantly more work needs to be done to empirically ground such a theoretical move.

A convincing argument could rely on evidence showing that sensory signals from the same region in the body are processed in different manners and lead to different bodily sensations. We could then relate differences in intentional mode to differences in the neural processing causing the respective sensations. While the assumption that visual and bodily sensations come along with different intentional modes is quite convincing (e.g., Bain, 2003), it is questionable whether corresponding evidence can be found in the direct comparison of bodily sensations. For example, pains and itches cannot, in large part at least, be distinguished in terms of the sensory processing causing the respective experiences. Pains and itches rely on the activity of similar receptors and are processed in the same network of anatomically defined neural structures (Forster \& Handwerker, 2014; Iannetti \& Mouraux, 2010; Mochizuki \& Kakigi, 2015)..$^{13}$

Fourth, one might object that the versions of strong representationalism discussed and, accordingly, my analysis too rely on a false presumption concerning the phenomenal character of bodily sensations. That is, there might be no unique phenomenal character shared by all experiences of pain, itches, and hunger. This assumption may be interpreted in two ways.

On the one hand, one might assume that pain, itches, and hunger actually have the same phenomenal character. Consequently, strong representationalists can account for their phenomenology in reference to the same intentional content, such as the representation of

${ }^{13}$ The question of whether the introduction of distinct intentional modes for different bodily sensations is empirically justified is closely related to the question of whether pain, itches, and hunger constitute distinct modalities. This issue has been discussed in more detail with respect to pain by Jennifer Corns (2014). 
physiological harm. As stated in the introduction, I accept that pain, itches, and hunger typically share the same negative affective valence. I merely assume that they differ in the sense that they are experienced as distinct bodily sensations. While humans might fail, in some cases, to clearly distinguish hunger from stomachache, or an itch from superficial healing pain, their phenomenal character at large is not identical. One might thus rephrase the conclusion of my investigations as a conditional: if strong representationalists accept that bodily sensations differ in terms of their unique phenomenal character, then their arguments from reliable causal covariance and biological function fail to plausibly motivate the introduction of different intentional contents for each.

On the other hand, one might assume that those cases which are considered to be instantiations of the same bodily sensation do not share a common phenomenal character. According to this view, different types of pain are not phenomenologically unified and, as such, they are determined by different intentional contents. The assumption that pains share a phenomenal character seems to be part of the common ground shared with strong representationalists who use the pains of burns, toothaches, backaches, headaches, and phantom pains as exemplary instantiations of the same mental phenomenon (Bain, 2007; Bain \& Brady, 2014; Tye, 1997). Again, the resulting conclusion can be stated conditionally: if strong representationalists accept that these cases share a phenomenal character, then their arguments from reliable causal covariance and biological function fail to plausibly motivate the introduction of a common intentional content. The same argument applies, in a similar manner, to other bodily sensations.

Fifth, one might altogether reject the claim that the intentional content of bodily sensations represents an objective condition in the world. This idea underlies theories of strong imperativism (Klein, 2015, 2017). Strong imperativism claims that the phenomenal character of bodily sensations is essentially and exhaustively determined by an intentional content, but this intentional content demands the performance of certain actions. Strong imperativism is attractive for multiple reasons. It preserves the advantage of providing a naturalistic theory of the phenomenal character of bodily sensations. It also avoids the objections previously outlined because it does not presuppose a reliable causal or biological connection between bodily sensations and particular bodily conditions. Moreover, strong imperativism highlights the motivational aspects of bodily sensations. This corresponds to previous insights indicating that the biological benefit of pain, hunger, itches, and sexual feelings might significantly rely on how they affect the way a subject acts in certain situations. 
Whether or not strong imperativism constitutes a plausible theory of pain and other bodily sensations cannot be discussed within the scope of this paper (see Coninx, 2020b). For now, it is sufficient to acknowledge that strong imperativism avoids the problems of strong representationalism while preserving its advantages. It constitutes a serious opponent. Strong imperativists challenge strong representationalists not merely with respect to the sensory features of bodily sensations (Klein, 2015, 2017), which have been the focus of this paper, but also with respect to their affective features (Barlassina \& Hayward, 2019). However, it is important to note that, in adopting strong imperativism, one rejects strong representationalism. Finally, it would also be conceivable to combine elements of strong representationalism and strong imperativism (Martínez, 2011). For now, it remains questionable whether the problems of representationalist theories can thereby be fully avoided. An at least partial abandonment of the core ideas of strong representationalism seems unavoidable.

\section{Conclusion}

This paper has aimed to show, against common intuitions, that arguments from reliable causal covariance and biological function do not favor a strong representationalist interpretation of bodily sensations. In particular, we have seen that pain, hunger, itches, and sexual feelings are related to a heterogeneous class of causes and biological functions. Various responses available to the strong representationalist were then considered. Some directly contradicted strong representationalism while others rejected assumptions that are common among its defenders, for example, those concerning the phenomenology of bodily sensations. We found that the most promising responses which are available to the strong representationalists require significantly more empirical proof than currently offered in order to ground strong representationalist arguments. It remains questionable whether such proof can be provided in the future. As a final move, one might altogether forsake the project of justifying the assumptions of strong representationalism with reference to the external relations between bodily sensations and conditions of the body. Whether or not other arguments can motivate the introduction of corresponding intentional contents must be the subject of further discussion. This is also the case for the question of whether alternative theories, such as strong imperativism, can ultimately account for bodily sensations. 


\section{References}

Amin, T., \& Mercer, J. G. (2016). Hunger and satiety mechanisms and their potential exploitation in the regulation of food intake. Current Obesity Reports, 5(1), 106-112.

Apkarian, A. V. (2017). Advances in the neuroscience of pain. In J. Corns (Ed.), Routledge handbook of philosophy of pain (pp. 73-86). New York: Routledge.

Apkarian, A. V., Baliki, M. N., \& Geha, P. Y. (2009). Towards a theory of chronic pain. Progress in Neurobiology, 87(2), 81-97.

Aydede, M. (2000). An analysis of pleasure vis-à-vis pain. Philosophy and Phenomenological Research, 61(3), 537-570.

Aydede, M. (2017). Pain: perception or introspection? In J. Corns (Ed.), Routledge handbook of philosophy of pain (pp. 221-232). New York: Routledge.

Aydede, M. (2019). Is the experience of pain transparent? Synthese, 196, 677-708.

Azimi, E., Xia, J., \& Lernera, E. A. (2016). Peripheral mechanisms of itch. Current Problems in Dermatology, 50, 18-23.

Bain, D. (2003). Intentionalism and pain. Philosophical Quarterly, 53(213), 502-523.

Bain, D. (2007). The location of pains. Philosophical Papers, 36(2), 171-205.

Bain, D. (2013). What makes pains unpleasant? Philosophical Studies, 166(1), 69-89.

Bain, D. (2014). Pains that don't hurt. Australasian Journal of Philosophy, 92(2), 305-320.

Bain, D. (2017). Evaluative accounts of pain's unpleasantness. In J. Corns (Ed.), Routledge handbook of philosophy of pain (pp. 40-50). New York: Routledge.

Bain, D., \& Brady, M. (2014). Pain, pleasure, and unpleasure. Review of Philosophy and Psychology, 5, 1-14.

Barlassina, L., \& Hayward, M. K. (2019). More of me! Less of me! Reflexive imperativism about affective phenomenal character. Mind, 128(512), 1013-1044.

Bhatt, J. M., Lin, H. W., \& Bhattacharyya, N. (2016). Prevalence, severity, exposures, and treatment patterns of Tinnitus in the United States. JAMA Otolaryngology: Head and Neck Surgery, 142(10), 959-965.

Bingel, U., \& Tracey, I. (2008). Imaging CNS modulation of pain in humans. Physiology, 23(6), 371-380.

Block, N. (1990). Inverted earth. Philosophical Perspectives, 4, 53-79.

Borg, G. (1998). Borg's rating of perceived exertion and pain scales. Champaign (IL): Human Kinetics.

Breivik, H., Collett, B., Ventafridda, V., Cohen, R., \& Gallacher, D. (2006). Survey of chronic pain in Europe: prevalence, impact on daily life, and treatment. European Journal of Pain, 10(4), 287-333.

Brooks, J., \& Tracey, I. (2005). From nociception to pain perception: imaging the spinal and supraspinal pathways. Journal of Anatomy, 207(1), 19-33.

Brotto, L., Atallah, S., Johnson-Agbakwu, C., Rosenbaum, T., Abdo, C., Byers, E. S., Graham, C., Nobre, P., \& Wylie, K. (2016). Psychological and interpersonal dimensions of sexual function and dysfunction. Journal of Sexual Medicine, 13(4), 538-571. 
Brown, J. L. (2003). Social support and experimental pain. Psychosomatic Medicine, 65(2), 276-283.

Burger, K. S., Sanders, A. J., \& Gilbert, J. R. (2016). Hedonic hunger is related to increased neural and perceptual responses to cues of palatable food and motivation to consume: evidence from 3 independent investigations. Journal of Nutrition, 146(9), 1807-1812.

Byrne, A. (2001). Intentionalism defended. Philosophical Review, 110(2), 199-240.

Carvalho, F. (2014). Olfactory objects. Disputatio, 6(38), 45-66.

Castro, J. B., \& Seeley, W. P. (2014). Olfaction, valuation, and action: Reorienting perception. Frontiers in Psychology, 5, 299.

Cavedon-Taylor, D. (2018). Odors, objects, and olfaction. American Philosophical Quarterly, 55(1), 81-94.

Coninx, S. (2020a). Experiencing pain. Berlin: de Gruyter.

Coninx, S. (2020b). Pain experiences and their link to action: challenging imperative theories. Journal of Consciousness Studies, 27(9-10), 104-126.

Corns, J. (2014). The inadequacy of unitary characterizations of pain. Philosophical Studies, 169(3), 355-378.

Corns, J. (2018). Recent work on pain. Analysis, 78(4), 737-753.

Crane, T. (2003). The intentional structure of consciousness. In A. Jokic \& Q. Smith (Eds.), Consciousness: new philosophical perspectives (pp. 33-56). Oxford: Oxford University Press.

Cutter, B. (2017). Pain and representation. In J. Corns (Ed.), Routledge handbook of philosophy of pain (pp. 29-39). New York: Routledge.

Cutter, B., \& Tye, M. (2011). Tracking representationalism and the painfulness of pain. Philosophical Issues, 21(1), 90-109.

Dahlhamer, J., Lucas, J., Zelaya, C., Nahin, R., Mackey, S., DeBar, L., Kerns, R., Von Korff, M., Porter, L., \& Helmick, C. (2018). Prevalence of chronic pain and high-impact chronic pain among adults - United States, 2016. Morbidity and Mortality Weekly Report, 67(36), 10011006.

Dretske, F. (1995). Naturalizing the mind. Cambridge (MA); London: MIT Press.

Eccleston, C., \& Crombez, G. (1999). Pain demands attention: a cognitive-affective model of the interruptive function of pain. Psychological Bulletin, 125(3), 356-366.

Fleischman, D. S. (2016). An evolutionary behaviorist perspective on orgasm. Socioaffective Neuroscience \& Psychology, 6, 32130.

Forster, C., \& Handwerker, H. O. (2014). Central nervous processing of itch and pain. In E. E. Carstens \& T. Akiyama (Eds.), Itch: mechanisms and treatment (pp. 409-420). Boca Raton (FL): Taylor \& Francis.

Gatchel, R. J., Peng, Y. B., Peters, M. L., Fuchs, P. N., \& Turk, D. C. (2007). The biopsychosocial approach to chronic pain: scientific advances and future directions. Psychological Bulletin, 133(4), 581-624.

Gozzano, S. (2019). Locating and representing pain. Philosophical Investigations, 42(4), 313332.

Grahek, N. (2007). Feeling pain and being in pain. Cambridge (MA); London: MIT Press. 
Hadjistavropoulos, T. (2017). Biopsychological models of pain. In J. Corns (Ed.), Routledge handbook of philosophy of pain (pp. 154-164). London; New York: Routledge.

Halder, S. L. S., \& Locke III, G. R. (2009). Epidemology and social impact of visceral pain. In M. A. Giamberardino (Ed.), Visceral pain: clinical, pathological and therapeutic aspects (pp. 1-8). Oxford: Oxford University Press.

Hall, R. J. (2008). If it itches, scratch! Australasian Journal of Philosophy, 86(4), 525-535.

Han, L., \& Dong, X. (2014). Itch mechanisms and circuits. Annual Review of Biophysics, 43, $331-355$.

Helms, E. R., Byrnes, R. K., Cooke, D. M., Haischer, M. H., Carzoli, J. P., Johnson, T. K., Cross, M. R., Cronin, J. B., Storey, A. G., \& Zourdos, M. C. (2018). RPE vs. Percentage 1RM loading in periodized programs matched for sets and repetitions. Frontiers in Physiology, 9, 247.

Hill, C. S. (2012). Locating qualia: do they reside in the brain or in the body and the world? In C. S. Hill \& S. Gozanno (Eds.), New perspectives on type identity: the mental and the physical (pp. 127-149). Cambridge (MA); London: Cambridge University Press.

Hill, C. S. (2017). Fault lines in familiar concepts of pain. In J. Corns (Ed.), Routledge handbook of philosophy of pain (pp. 60-69). New York: Routledge.

Howick, J., Friedemann, C., Tsakok, M., Watson, R., Tsakok, T., Thomas, J., Perera, J., Fleming, S., \& Heneghan, C. (2013). Are treatments more effective than placebos? A systematic review and meta-analysis. PLoS ONE, 8(5), e62599.

Huh, J., Shiyko, M., Keller, S., Dunton, G., \& Schembre, S. M. (2015). The time-varying association between perceived stress and hunger within and between days. Appetite, 89, 145151.

Iannetti, G. D., \& Mouraux, A. (2010). From the neuromatrix to the pain matrix (and back). Experimental Brain Research, 205(1), 1-12.

Ilgen, M. A., Zivin, K., Austin, K. L., Bohnert, A. S. B., Czyz, E. K., Valenstein, M., \& Kilbourne, A. M. (2010). Severe pain predicts greater likelihood of subsequent suicide. Suicide \& Life-Threatening Behavior, 40(6), 597-608.

Jacobson, H. (2013). Killing the messenger: representationalism and the painfulness of pain. Philosophical Quarterly, 63(252), 509-519.

Keltner, J. R. (2006). Isolating the modulatory effect of expectation on pain transmission: a functional magnetic resonance imaging study. Journal of Neuroscience, 26(16), 4437-4443.

Key, B. (2015). Fish do not feel pain and its implications for understanding phenomenal consciousness. Biology and Philosophy, 30(2), 149-165.

Klein, C. (2015). What the body commands - the imperative theory of pain. Cambridge (MA); London: MIT Press.

Klein, C. (2017). Imperativism. In J. Corns (Ed.), Routledge handbook of philosophy of pain (pp. 51-59). New York: Routledge.

Komisaruk, B. R., \& Whipple, B. (2011). Non-genital orgasms. Sexual and Relationship Therapy, 26(4), 365-372.

Lavery, M. J., Kinney, M. O., Mochizuki, H., Craig, J., \& Yosipovitch, G. (2016). Pruritus: an overview. What drives people to scratch an itch? Ulster Medical Journal, 85(3), 164-173. 
Longo, M. R., Betti, V., Aglioti, S. M., \& Haggard, P. (2009). Visually induced analgesia: seeing the body reduces pain. Journal of Neuroscience, 29(39), 12125-12130.

Machin, K. L. (2001). Fish, amphibian, and reptile analgesia. The Veterinary Clinics of North America, 4(1), 19-33.

Martínez, M. (2011). Imperative content and the painfulness of pain. Phenomenology and the Cognitive Sciences, 10(1), 67-90.

Mayer, J. (1996). Glucostatic mechanism of regulation of food intake. Obesity Research, 4(5), 493-496.

McGinn, C. (1996). The character of mind: an introduction to the philosophy of mind (2nd ed.). Oxford: Oxford University Press.

Melzack, R., \& Wall, P. D. (1982). The challenge of pain (2nd ed.). London: Penguin Books.

Melzack, R., Wall, P. D., \& Weisz, A. Z. (1963). Masking and metacontrast phenomena in the skin sensory system. Experimental Neurology, 8(1), 35-46.

Miles, M. P., \& Clarkson, P. M. (1994). Exercise-induced muscle pain, soreness, and cramps. Journal of Sports Medicine and Physical Fitness, 34(3), 203-216.

Millikan, R. G. (2004). Varieties of meaning: the 2002 Jean Nicod Lectures. Cambridge (MA); London: MIT Press.

Misery, L. (2016). Psychogenic pruritus. In L. Misery \& S. Ständer (Eds.), Pruritus (pp. 307312). New York: Springer.

Misery, L., Dutray, S., Chastaing, M., Schollhammer, M., Consoli, S. G., \& Consoli, S. M. (2018). Psychogenic itch. Translational Psychiatry, 8(1), 52.

Mizumura, K., \& Taguchi, T. (2016). Delayed onset muscle soreness: involvement of neurotrophic factors. Journal of Physiological Sciences, 66(1), 43-52.

Mochizuki, H., \& Kakigi, R. (2015). Central mechanisms of itch. Clinical Neurophysiology, 126(9), 1650-1660.

Murase, S., Terazawa, E., Queme, F., Ota, H., Matsuda, T., Hirate, K., Kozaki, Y., Katanosaka, K., Taguchi, T., Urai, H., \& Mizumura, K. (2010). Bradykinin and nerve growth factor play pivotal roles in muscular mechanical hyperalgesia after exercise (delayed-onset muscle soreness). Journal of Neuroscience, 30(10), 3752-3761.

Nagasako, E. M., Oaklander, A. L., \& Dworkin, R. H. (2003). Congenital insensitivity to pain: an update. Pain, 101(3), 213-219.

Nekoolaltak, M., Keshavarz, Z., Simbar, M., Nazari, A. M., \& Baghestani, A. R. (2017). Women's orgasm obstacles: a qualitative study. International Journal of Reproductive Biomedicine, 15(8), 479-490.

Nosaka, K. (2008). Muscle soreness and damage and the repeated-bout effect. In P. M. Tiidus (Ed.), Skeletal muscle damage and repair (pp. 59-76). Champaign (IL): Human Kinetics.

Pitcher, G. (1970). Pain perception. Philosophical Review, 79(3), 368-393.

Ploner, M., Bingel, U., \& Wiech, K. (2015). Towards a taxonomy of pain modulations. Trends in Cognitive Sciences, 19(4), 180-182.

Raja, S. N., Carr, D. B., Cohen, M., Finnerup, N. B., Flor, H., Gibson, S., Keefe, F. J., Mogil, J. S., Ringkamp, M., Sluka, K. A., Song, X.-J., Stevens, B., Sullivan, M. D., Tutelman, P. R., Ushida, T., \& Vader, K. (2020). The revised International Association for the Study of Pain 
definition of pain: concepts, challenges, and compromises. Pain. 10.1097/j.pain.0000000000001939

Rhudy, J. L. (2016). Emotional modulation of pain. In M. Al'Absi \& M. A. Flaten (Eds.), The neuroscience of pain, stress, and emotion: psychological and clinical implications (pp. 51-75). Amsterdam: Elsevier.

Safron, A. (2016). What is orgasm? A model of sexual trance and climax via rhythmic entrainment. Socioaffective Neuroscience \& Psychology, 6, 31763.

Sneddon, L. U. (2015). Pain in aquatic animals. Journal of Experimental Biology, 218, 967976.

Sneddon, L. U., Elwood, R. W., Adamo, S. A., \& Leach, M. C. (2014). Defining and assessing animal pain. Animal Behaviour, 97, 201-212.

Strigo, I. A., Bushnell, M. C., Boivin, M., \& Duncan, G. H. (2002). Psychophysical analysis of visceral and cutaneous pain in human subjects. Pain, 97(3), 235-246.

Treede, R. D., Rief, W., Barke, A., Aziz, Q., Bennett, M. I., Benoliel, R., Cohen, M., Evers, S., Finnerup, N. B., First, M. B., Giamberardino, M. A., Kaasa, S., Korwisi, B., Kosek, E., Lavand'Homme, P., Nicholas, M., Perrot, S., Scholz, J., Schug, S., Smith, B. H., Svensson, P., Vlaeyen, J. W. S., \& Wang, S. J. (2019). Chronic pain as a symptom or a disease: the IASP Classification of Chronic Pain for the International Classification of Diseases (ICD-11). Pain, 160(1), 19-27.

Tye, M. (1995). Ten problems of consciousness. Cambridge (MA); London: MIT Press.

Tye, M. (1997). A representational theory of pains and their phenomenal character. In N. Block, O. Flanagan, \& G. Güzeldere (Eds.), The nature of consciousness: philosophical debates (pp. 329-341). Cambridge (MA); London: MIT Press.

Tye, M. (2005). Another look at representationalism about pain. In M. Aydede (Ed.), Pain: new essays on its nature and the methodology of its study (pp. 99-120). Cambridge (MA); London: MIT Press.

Tye, M. (2007). Orgasms Again. Philosophical Issues, 7, 51-54.

Tye, M. (2017). Are pains feelings? The Monist, 100(4), 478-484.

Williams, A. C. de C. (2017). Psychological models of pain. In J. Corns (Ed.), Routledge handbook of philosophy of pain (pp. 143-153). New York: Routledge.

Wolkers, C. P. B., Barbosa Junior, A., Menescal-de-Oliveira, L., \& Hoffmann, A. (2013). Stress-induced antinociception in fish reversed by naloxone. PLoS ONE, 8(7), e71175.

Zourdos, M. C., Klemp, A., Dolan, C., Quiles, J. M., Schau, K. A., Jo, E., Helms, E., Esgro, B., Duncan, S., Garcia Merino, S., \& Blanco, R. (2016). Novel resistance training-specific rating of perceived exertion scale measuring repetitions in reserve. Journal of Strength and Conditioning Research, 30(1), 267-275. 